JUAN FRANCISCO TURRIENTES

SANTIAGO, CHILE

TURRIENTES@VTR.NET

\section{Del rollo de papiro al libro impreso. Algunas notas históricas acerca de la formación de la página}

\author{
From papyrus scroll to printed book \\ Some historical notes on the building of the page
}

Resumen. Este artículo pretende rastrear algunas coordenadas fundamentales de la evolución de la página en tanto elemento constitutivo del libro a lo largo del tiempo. Se busca describir algunos de sus desarrollos, que han respondido tanto a las transformaciones del libro en tanto transmisor de textos como a las necesidades prácticas de sus productores y sus usuarios, los lectores. Esta evolución es un proceso continuo que se alimenta de las experiencias y tradiciones previas, pone en movimiento una voluntad persistente de organizar la información sobre la página, entendiéndola como un dispositivo de transmisión de conocimiento.

Palabras clave: evolución de la página, incunables, historia del libro, libro impreso, manuscritos.

\begin{abstract}
This article intends to trace over the course of time some of the fundamental coordinates in the evolution of the page, as a constituent element of the book. It seeks to describe some of the developments that have responded to the transformation of the book as a text transmitter, as well as to the practical needs of its producers and users, the readers. This evolution is a continuous process that feeds on previous experiences and traditions, setting into motion a persistent will to organize the information on the page, understanding it as a device to transmit knowledge.
\end{abstract}

Keywords: History of the Book, Incunabula, Manuscripts, Page evolution, Printed Book.
Fecha de recepción: 01/04/2019

Fecha de aceptación: 22/05/2019

Cómo citar: Turrientes, J. (2019) Del rollo

de papiro al libro impreso. Algunas notas

históricas acerca de la formación de la página.

RChD: creación y pensamiento, 4 (6), 1-15

DOI: 10.5354/0719-837X.2019.52695
Revista Chilena de Diseño,

RChD: creación y pensamiento

Universidad de Chile

2019, 4(6)

http://rchd.uchile.cl 
La página es una zona expresiva para el texto, el espacio y la imagen; es un artefacto cultural; es un dispositivo tecnológico.

Pero también es todas estas cosas a la vez.

Bonnie Mak, How the Page Matters

\section{Introducción}

No siempre la página -impresa o manuscrita- se configuró del modo en que la conocemos hoy. Como elemento constitutivo del libro evolucionó de acuerdo con las necesidades de transmisión de los textos, las prácticas de lectura y los modos de producción de los soportes sobre los que se construía. Las formas históricas de la página han respondido a las modificaciones que el libro ha sufrido como soporte. Esta evolución no fue siempre lineal y está marcada por avances, retrocesos y anticipaciones. Muchas de las innovaciones en su desarrollo surgieron como nuevas síntesis de prácticas anteriores y respondieron tanto a los experimentos y tentativas de los productores de libros como a las necesidades materiales que debieron enfrentar.

\section{Metodología}

Esta investigación fue desarrollada fundamentalmente en tres fases de estudio. Por un lado, se realizó un análisis de fuentes primarias -archivos bibliográficos, archivos digitales de manuscritos e incunables, ejemplares físicos de libros impresos- que permitiera analizar los modos característicos y recurrentes de composición de la página en diferentes momentos históricos y en diferentes soportes de reproducción de textos, a partir de la observación de ejemplares determinados. En segundo lugar, se desarrolló un estudio de fuentes secundarias -material bibliográfico disponible en textos históricos, ensayos, investigaciones y estudios teóricos pertinentes- acerca del libro como producto cultural, para detectar sus principales variables de desarrollo y transformación, para elaborar una lectura consistente de la evolución de la página como dispositivo del libro.

Por último, se ha realizado un análisis de la información reunida, con el objeto de articularla en una mirada válida que nos permita recoger las principales etapas de desarrollo de la página y su relación histórica con las transformaciones sufridas en los modos de producción del libro.

\section{El rollo de papiro y la columna de texto}

Pagina era la palabra latina para designar las columnas de texto inscritas en los antiguos rollos de papiro. Alrededor del año 3000 a. C., en el Antiguo Egipto, se comenzó a fabricar el papiro a partir de los tallos de esa planta, especialmente abundante en el valle del Nilo, que era cultivada bajo un estricto control gubernamental. Esas columnas - paginae, en plural- constituían el modo fundamental de disponer el texto sobre el rollo de papiro, que era la forma convencional del libro y el soporte de escritura dominante en la antigüedad grecorromana (Gamble, 1995).

El tamaño de la hoja de papiro estaba restringido por las limitaciones naturales de la planta, cuyos tallos utilizables raramente excedían los 40 centímetros de largo. Una hoja individual podía variar entre los 10 y los 29 centímetros de ancho, y entre 20 y 30 centímetros de alto (Mak, 2011). Para formar los rollos de papiro las hojas eran alineadas y superpuestas levemente unas a otras, para luego unirlas aplicando goma en el pequeño traslape que se producía en el borde derecho de la hoja, que era montado sobre el 


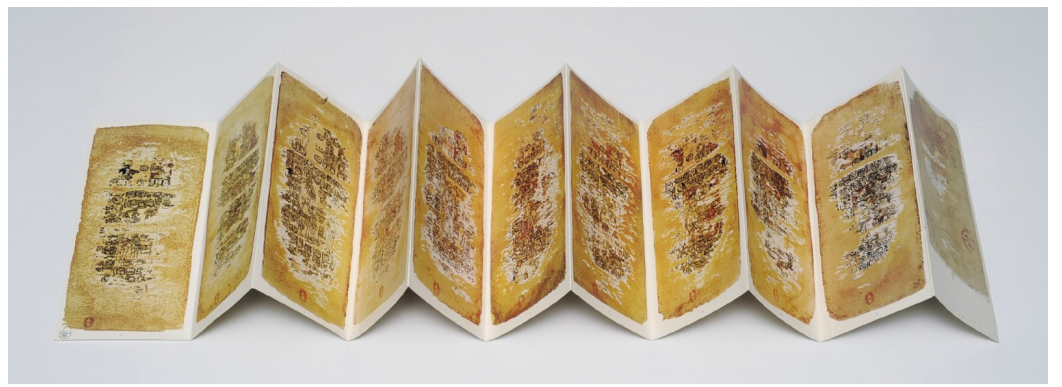

borde izquierdo de la siguiente. La extensión de los rollos dependía más de la conveniencia del lector que de su manufactura, pues una mayor extensión del volumen volvía su manipulación más dificultosa. Los rollos egipcios podían llegar a medir 20 metros, mientras los griegos alcanzaban cerca de 10 metros de longitud. Se escribía de izquierda a derecha y en columnas de 6 a 9 centímetros de ancho por 15 a 24 de alto, los que se organizaban en series sucesivas, en ocasiones pasando sobre las junturas de las hojas. Así, la proximidad de una pagina con otra requería desplegar el rollo por secciones, para estimular una práctica de lectura continua.

Las diferentes formas de componer la pagina sobre su soporte parecen responder a los tipos de textos copiados y al estatus pretendido del volumen. En muchos rollos sobrevivientes escritos en verso, por ejemplo, el ancho de las columnas es de alrededor de 15 centímetros, mientras las de los escritos en prosa tendían a ser más altas y delgadas, bordeando los 607 centímetros de ancho. Las paginas de los rollos de lujo, por otra parte, eran menores en sus dimensiones y disponían de márgenes más anchos.

Las subdivisiones de las obras en libros eran determinadas tanto por la longitud de los rollos como por divisiones previamente incorporadas en el texto por sus autores. Las obras más extensas sufrían la imposición externa de divisiones al ser copiadas en varios volúmenes, mientras los autores de nuevas obras establecían sus propias formas de seccionar el texto adaptándose a las extensiones convencionales de los rollos de papiro. En estos casos la unidad del rollo funcionaba también como una unidad literaria.

La organización de las columnas parece sugerir que la pagina era entendida como una interfaz flexible que podía ser adaptada en tamaño, forma y disposición, de acuerdo a las necesidades del escriba y el lector: el copista dividía visualmente el rollo de papiro en unidades discretas -los bloques de texto- utilizando las columnas como una estructura conceptual que organizaba la información. El texto se desplegaba sobre el rollo de acuerdo a sus límites materiales, desafiando así la idea de que la página debía tener una forma específica y particular (Mak, 2011).

Algunos rollos eran plegados a la manera de un biombo, con las columnas circunscritas entre sus pliegues, utilizando los vacíos entre las columnas como guías y reforzando los límites del texto. En el siglo XVI, los conquistadores españoles se encontraron en Centroamérica con comunidades mayas y aztecas que habían desarrollado una forma similar de producir rollos de āmatl, un material fabricado a partir de cortezas de árbol y utilizado para la fabricación de āmoxtli: libros de hojas pegadas consecutivamente que formaban un rollo plisado a la manera de un biombo o un acordeón (Figura 1).
Figura 1. Codex Peresianus, 1250-1520. SLUB Dresden. 


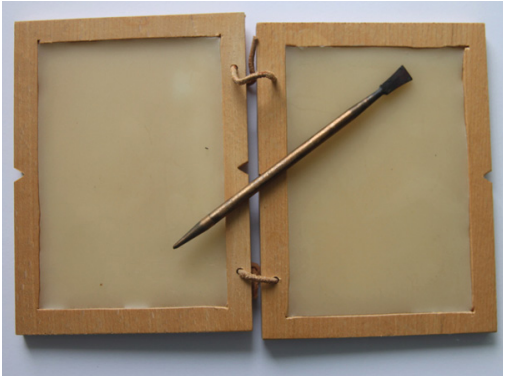

Figura 2. Tableta romana y stilus. Reconstrucción de Peter van der Sluijs
Gracias a la destructiva diligencia de los conquistadores, solo un puñado de estos libros ha sobrevivido. Entre ellos, el Codex Peresianus, compuesto de páginas de alrededor de 25 centímetros de alto por 13 de ancho, cuya manufactura se sitúa entre los años 1250 y 1520 (Houston, 2016). En esta forma de administrar el rollo ya podemos encontrar implícito el gesto de circunscribir la página y definir ciertos límites sobre los que el texto se desplegará. Más adelante, con la invención del códice, la definición de los límites de la página como soporte material consolidaría ese gesto.

\section{Aparición del códice}

La expresión latina cōdex, que puede significar bloque de madera, pero también bloque de madera dividido en tablones, hojas o tabletas y atados juntos refiere a las tabletas rectangulares de madera utilizadas como soporte de escritura en la antigua Roma. La configuración más común era la de dos tabletas unidas entre sí por medio de una cuerda o una delgada correa, produciendo una superficie mayor para la escritura y permitir cerrarlas, lo que facilita su transporte y protege el texto. La superficie de la tableta era ahuecada levemente y luego rellenada con cera. Sobre ella se escribía utilizando un punzón de metal (stilus), con cuyo reverso podía borrarse lo escrito. La cultura romana antigua distinguía entre las tabletas de mayor tamaño (tabellae) y las más pequeñas, que cabían en una mano, llamadas pugillares (Figura 2).

La página se vio circunscrita materialmente con la tableta, convirtiéndose esta en una unidad discreta y adquiriendo identidad como "espacio aprobado para la lectura y la escritura": "El encuadre de la tableta marca los bordes del espacio cognitivo de la página, entregando claras indicaciones acerca de dónde la información debía ser inscrita y leída" (Mak, 2011, p. 13).

Las tabletas servían de soporte para textos de carácter transitorio, como cuentas, ejercicios escolares, notas y registros documentales. Este carácter utilitario se mantuvo cuando fueron reemplazadas por hojas de papiro o pergamino, plegadas y atadas entre sí. El cōdex así construido resultaba más liviano y fácil de manejar y aunque su escritura requería del uso de tinta podía ser reutilizado, dado que las hojas podían ser lavadas o frotadas para volver a disponer de una superficie limpia.

No sabemos en qué momento exacto ni en qué lugar preciso apareció por primera vez el libro de pergamino. Alrededor del año 95, Quintiliano hace referencia al pergamino como soporte de escritura en las Instituto oratoria y el poeta Marcial entrega una evidencia temprana de este desarrollo en sus Epigrammata, donde recomienda a los lectores que deseen viajar con sus poemas comprar "aquellos que el pergamino contiene en pequeñas páginas" y que pueden ser sostenidos en una mano. Además, identifica al librero que los ofrecía: Secundus, detrás de la puerta del templo de la Paz y el foro de Pallas (Houston, 2016). Los comentarios de Marcial parecen implicar la novedad de este soporte, pero no nos entregan indicaciones precisas acerca de su origen (Gamble, 1995). Los primeros cristianos adoptaron el códice como forma de transmisión literaria más rápidamente que sus contemporáneos. Para Gamble (1995), esta decisión se relacionaba con sus ventajas como soporte de escritura: permitía contener un repertorio de obras en un orden determinado y hacer referencias al texto con mayor facilidad. En contraste con el acceso secuencial que exigía el rollo, el códice le permitía al lector dirigirse aleatoriamente a una sección del texto o a un elemento particular de una colección de textos, que responde mejor a sus propias prácticas de lectura. 


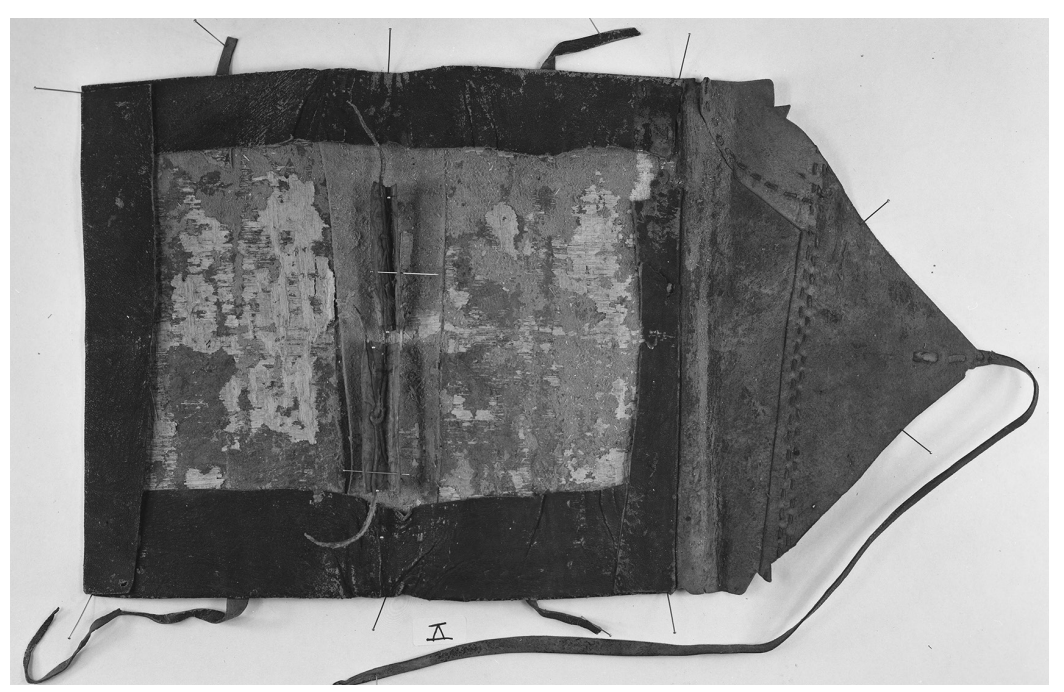

En 1945, cerca de la ciudad de Nag Hammadi, en el Alto Egipto, dos hermanos que buscaban fertilizantes para sus campos de cereales descubrieron una colección de libros cubiertos en cuero y una pequeña cantidad de hojas sueltas de papiro. Cada uno de los doce volúmenes encontrados -conocidos como los Códices de Nag Hammadi- estaba hecho de un conjunto de hojas de papiro que habían sido plegadas por la mitad y cosidas a una cubierta de cuero de oveja o de cabra. Los códices medían cerca de 30 centímetros de alto y alrededor de 45 extendidos, y muchas de sus cubiertas se desplegaban de tal manera que podían envolver el libro cerrado (Figura 3). Además, disponían de largas y delgadas correas de cuero que permitían mantenerlos cerrados, y de pequeños trozos de pergamino o cuero que reforzaban las costuras de la encuadernación (Houston, 2016).

Al desmontar las cubiertas -que habían sido reforzadas con restos de hojas de papiro- se encontraron cartas, contratos y documentos contables con distintas fechas, correspondientes a los años 333, 341, 346 y 348. Podemos suponer, entonces, que el ejemplar disponible más antiguo de un libro completamente encuadernado proviene del siglo IV. Estos volúmenes nos muestran cómo eran fabricados los primeros códices y nos recuerdan que la encuadernación como tecnología está anclada a los orígenes del libro:

Se trata del gesto que funda el propio libro y que, a partir de tres procedimientos básicos -la reunión de los cuadernos, la unión de los folios a través de una costura y la realización de una cubierta-, dio origen a las unidades codicológicas que definen (...) los aspectos físicos de los soportes de la palabra escrita desde los primeros siglos de nuestra era: la unidad de la página, la unidad del cuaderno, la unidad del códice, forma que hoy todavía es la nuestra. (Utsch, 2014, p. 160)

El lomo del códice permite unir múltiples cuadernos y sus folios ofrecen un espacio útil para la transmisión de ideas enfrentando -con el libro abiertodos páginas que sostienen una fuerte relación en razón de su contigüidad y serán percibidas simultáneamente por el lector, ofreciéndole un encuadre más amplio que resulta de la suma de ambas páginas individuales (Mak, 2011).
Figura 3. Cubierta y encuadernación. Nag Hammadi Archive, Claremont Colleges Digital Library. 


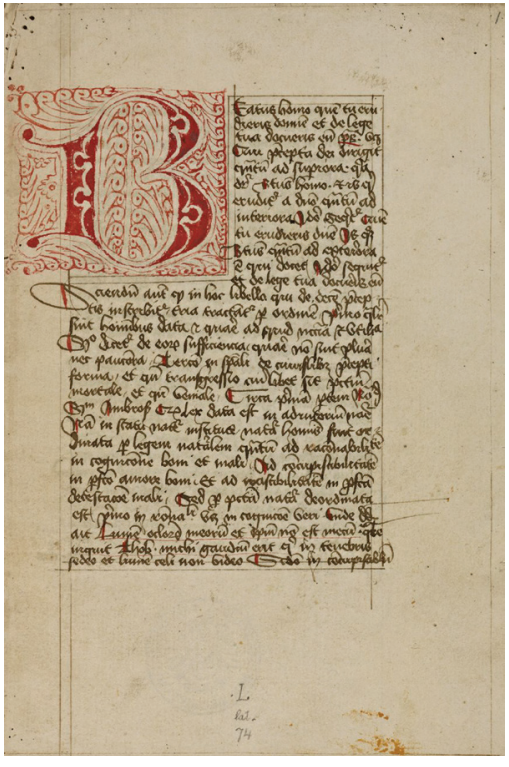

Figura 4. Folio trazado de pergamino. Manuscrits latins. Henrici de Frimaria proeceptorium, etc., siglo $\mathrm{XV}$, folio $\mathrm{ir}$. Bibliothèque nationale de France.
Las páginas de los Códices de Nag Hammadieran más altas que anchas, y la disposición vertical de las columnas evidenciaba la herencia recibida de la antigua forma de organizar el texto en los rollos de papiro. Formas similares de componer las columnas pueden encontrarse en libros producidos con otros formatos de página. El Codex Sinaiticus -la más antigua versión completa del Nuevo Testamento, copiado en griego a mediados del siglo IV-, con un formato prácticamente cuadrado -38 centímetros de largo por 34,5 de ancho-, dispone verticalmente el texto, compuesto en cuatro columnas de un ancho cercano a los 5,5 centímetros y con una altura de 24,5 .

\section{La página medieval}

Los manuscritos copiados durante la primera mitad de la Edad Media expresaban unos principios compositivos tendientes a producir jerarquías en la página, a estructurar el texto y a proporcionarle al lector las herramientas de navegación necesarias para su adecuada lectura. Los iluminadores y copistas elaboraron maneras de configurar la página que procedían de los antiguos rollos manuscritos, pero que se movían hacia un nuevo modo de disponer el texto en el códice.

La página medieval producida en los scriptoria medievales era una página planeada antes de su ejecución. Producir un manuscrito requería, antes que nada, trazar el folio de pergamino, para habilitar un espacio posible de escritura. Esta operación práctica -marcar los bordes del bloque de texto con líneas horizontales y verticales y señalar el intervalo entre unas líneas y otras- requería de una idea previa de cómo se construiría la página y se organizarían sus elementos.

El escriba necesitaba decidir previamente qué tamaño tendrían las iniciales y qué lugar ocuparían las miniaturas, pues debía reservar el espacio apropiado para ellas. La estructura implícita en la disposición del texto, así como las categorías asignadas a sus elementos decorativos, debía ser imaginada previamente (Figura 4).

La página medieval frecuentemente se organizaba en torno a una inicial capitular, la que operaba como una indicación para la lectura y señalaba una jerarquía en el texto. Las capitulares más grandes y más generosamente decoradas marcaban los comienzos de las secciones más importantes y las iniciales más pequeñas indicaban subdivisiones dentro del texto o el inicio de secciones de menor importancia. Todas estas señales eran reforzadas por la materialidad de los pigmentos utilizados: el oro, la pintura y la tinta como material de escritura expresaban categorías de importancia descendente de los textos manuscritos (Rudy, 2016).

En algunos manuscritos de los siglos VIII y IX, el incipit ${ }^{1}$ actuaba como un elemento estructurador del contenido de la página. En este periodo el texto se desplegaba como un flujo continuo, interrumpido ocasionalmente por indicaciones que marcaban sus diferentes momentos. El incipit se ubica dentro de ese flujo intentando no interrumpir la cadena de lo escrito, constituyéndose en un dispositivo de fraccionamiento del texto, que hace visibles sus partes a la vez que asegura su continuidad y su unidad.

Como sucedía con las capitulares, el mayor o menor grado de ornamentación de los incipit hacía manifiestas las distintas categorías implícitas al interior del texto. En los Evangelios de Lindau, copiados a fines del siglo IX en la abadía de Saint Gall, podemos encontrar incipit monumentales destinados a introducir a cada uno de los evangelistas. Al iniciar el texto de Marcos, el 


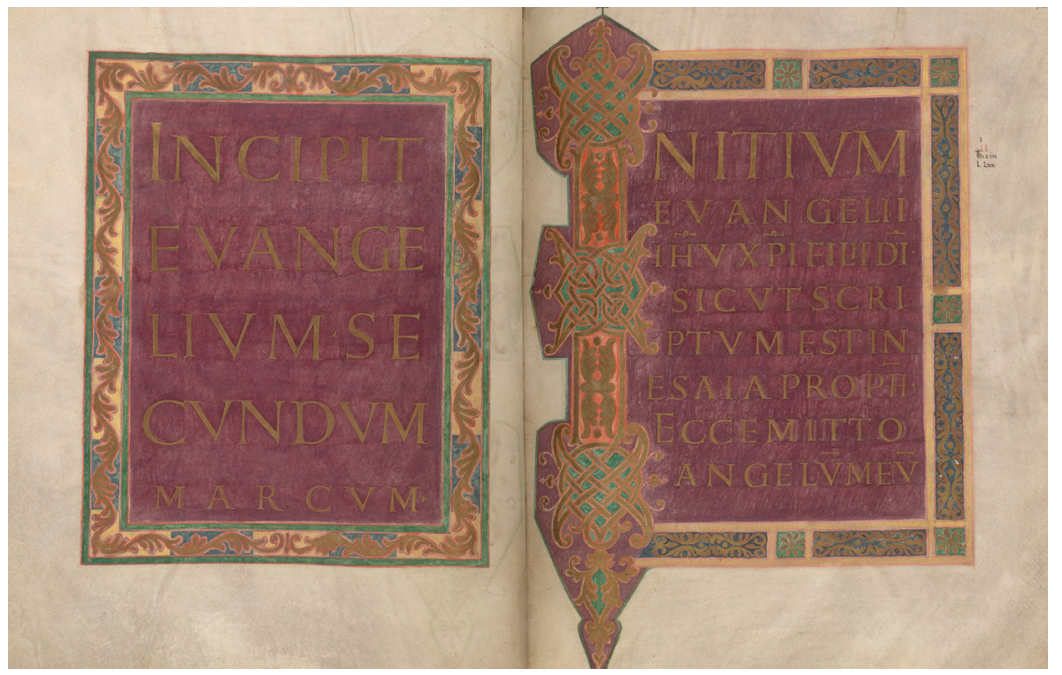

copista decidió disponer el nombre de la obra en la página izquierda -Incipit evangelium segundum Marcum - y sus primeras palabras copiadas a gran tamaño en la página derecha, entregándole al lector una señal inequívoca acerca de la categoría del texto que se preparaba a leer (Figura 5). Los encabezados de página no son muy frecuentes antes del siglo XIII, pero aparecen ocasionalmente en algunos códices entre los siglos VIII y X, prefigurando futuras prácticas de la producción de libros. Un manuscrito copiado alrededor del año 770 en Saint Gall utiliza este recurso verbal para identificar los distintos libros copiados en el volumen. En la página izquierda podemos leer la palabra Liber, y en la que se le enfrenta está inscrito el nombre del texto pertinente: "Deuteronomio".

Con el tiempo, estos dispositivos se volverían más sofisticados y adquirirían formas más consistentemente reglamentadas, pero la pretensión de copistas e iluminadores de articular la información volcada en los códices en función de su adecuada jerarquización y lecturabilidad se expresó claramente desde la primera mitad de la Edad Media.

A partir del siglo XII, los libros comenzaron a ser utilizados intensivamente en las universidades, produciéndose un fuerte aumento en la demanda de textos para alumnos y profesores. Aunque se siguieron copiando manuscritos en los scriptoria monacales, la producción de libros se trasladó desde los monasterios hacia el mundo académico y secular. La necesidad de multiplicar los textos impulsó la creación de talleres capaces de satisfacer esa nueva demanda. La figura del copista secular se desarrolló en medio de un proceso de urbanización y crecimiento de los centros poblados, mientras la aparición del papel -un soporte considerablemente menos costoso- favorecía la producción de libros y el aumento de la circulación de textos.

En torno de la universidad se articuló una cadena de reproducción de libros en la que intervinieron diversos actores con funciones especializadas: copistas, iluminadores, correctores y encuadernadores. El estacionario -que vendía, compraba, revendía y arrendaba textos bajo el control de la universidad- era el responsable de la copia y distribución de los libros, de la fidelidad de los textos y de la conservación de los volúmenes.

Por su naturaleza, el trabajo académico requería un aparato organizacional del códice que permitiera a profesores y estudiantes ejecutar sus particula-
Figura 5. Evangelios de Lindau, Abadía de Saint Gall, ca. 880-890. The Morgan Library \& Museum.

1. "La palabra latina incipit [...] era frecuentemente usada por autores medievales, algunas veces resaltada en los manuscritos por medio de rubricaciones o mayúsculas, antes o en lugar de un título, para denotar el inicio de una nueva obra o texto" (Beal, 2008 p. 196). 
Figura 6. Partie de l'Ancien Testament, siglo XIII. Fragmentos del Antiguo Testamento rodeados por la glossa ordinaria atribuida a Walafrid Strabon, además de las glosas interlineares de Anselmo de Laon, 1250-1299. Ms. 20, Bibliothèque municipale de Toulouse.

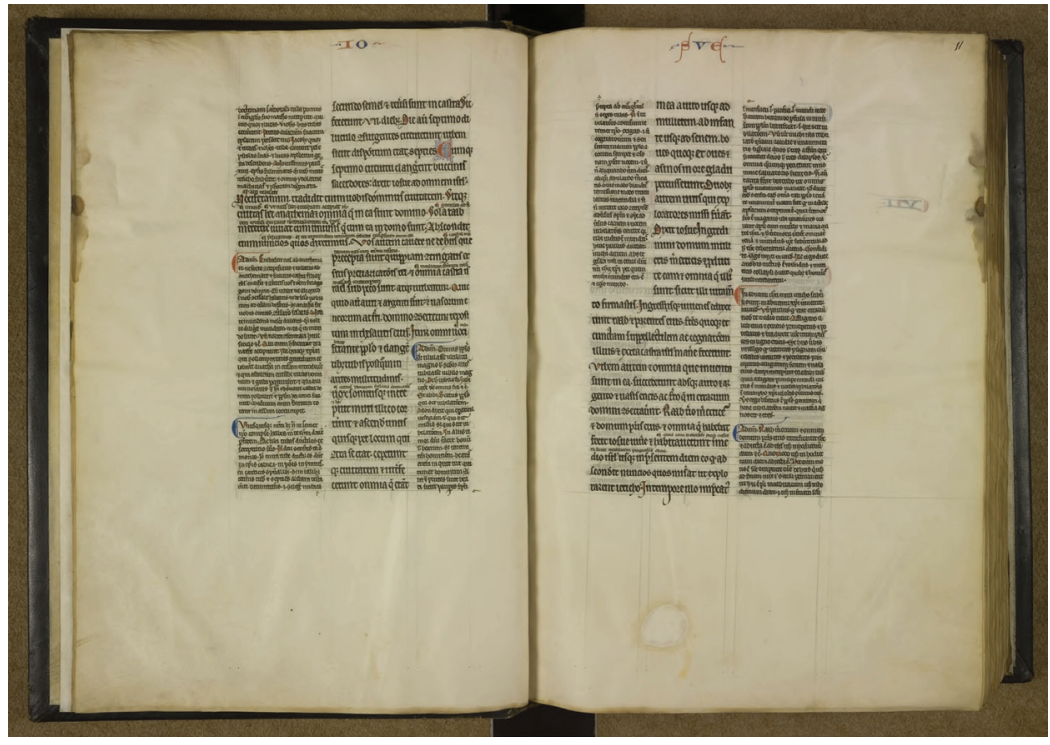

res prácticas de lectura, marcadas por la necesidad de orientarse en el texto. Los productores de libros debieron volver su mirada al ordenamiento sistemático de la información en la página, para producir una nueva organización interna del códice, con divisiones más evidentes y racionales.

La necesidad de disponer las glosas sobre la superficie de la página -en sus márgenes, rodear el texto o utilizar los intersticios entre una línea y otra- desafió a los escribas a estructurar el espacio sobre la página de una manera más sofisticada, para articular al menos dos categorías de texto que fluían simultáneamente a lo largo del volumen, que contenían citas, referencias a las auctoritates y notas al margen o al pie del texto. Un manuscrito de la segunda mitad del siglo XIII -Partie de l'Ancien Testamentcontiene diferentes fragmentos del Antiguo Testamento rodeado por la glossa ordinaria -que se despliega en torno del texto que comenta- atribuida a Walafrid Strabon, además de las glosas interlineares -ubicadas en los intersticios entre las líneas manuscritas- de Anselmo de Laon (Figura 6). El copista despliega los textos y secciona estructuralmente la página en función de sus contenidos con una gran sofisticación.

Durante el siglo XIII, las tablas de contenidos, índices y herramientas sistemáticas de referencia reforzarían la organización de la información contenida en los códices. Los primeros índices temáticos fueron las distinctiones -la primera herramienta textual de carácter alfabético si descontamos los diccionarios-, colecciones de significados de términos encontrados en las Escrituras, que se siguieron produciendo hasta el XIV. A finales del siglo XIII, los índices temáticos ya eran considerados una herramienta fundamental de lectura de textos teológicos, filosóficos y jurídicos. Por ese entonces, los libros ya disponían de encabezados de página, títulos de capítulos y tablas de contenidos que registraban las subdivisiones del texto. La página del libro se organizaba y tomaba forma: hacia 1400 el único elemento faltante en la estructura fundamental de los códices era la página de títulos (Kilgour, 1998).

A mediados del siglo XIV, los Libros de Horas - destinados a la devoción privada- se comenzaron a distribuir extensamente en Francia, Inglaterra 
y los Países Bajos. Contenían ciertos textos convencionales, pero su orden dentro del volumen no estaba reglamentado y en ocasiones incorporaban contenidos no programados, como algunas oraciones especialmente populares entre los fieles. Eran leídos según las necesidades de sus propietarios en un tiempo determinado: el momento litúrgico del año o los intereses personales de sus lectores podían determinar qué textos leer en un instante determinado de su vida cotidiana (Rudy, 2016).

Alrededor de 1390, en Brujas, se produjo una importante innovación: un grupo de iluminadores conocidos como los Maestros del Baldaquín Rosa comenzaron a producir miniaturas a página completa en talleres separados de aquellos en los que los textos eran copiados, para luego insertarlas en los libros antes de su encuadernación. La especialización de los talleres produjo un tipo de división del trabajo que, además de optimizar la producción, estandarizó y simplificó la imaginería utilizada.

Las imágenes se volvieron flexibles e intercambiables, convirtiéndose en piezas modulares y replicables que podían ser incorporadas a diferentes volúmenes de características similares. El libro es producido como una serie de componentes -miniaturas y folios manuscritos-, ensamblados modularmente y que pueden ser encuadernadas con diferentes configuraciones. Este sistema de ensamblaje multiplicaba los espacios en blanco en las páginas del códice: el propietario del manuscrito encontraba vacíos al final de un cuadernillo o en el reverso de las iluminaciones a página completa y sentía la necesidad de llenarlos con nuevos textos. Generaciones de propietarios personalizaron sus libros añadiéndoles textos, imágenes y objetos, reforzando sus contenidos y resignificando el códice. Muchos lectores ingleses de los Libros de Horas contrataron copistas profesionales para añadir breves oraciones en los espacios en blanco con que se encontraban. En un libro del siglo XIV manufacturado en Brujas (Ms. li.6.2)2 fue agregada una oración al reverso de una imagen de San Miguel (folio 14r), y unos folios más adelante (33r) el propietario del códice añadió las fechas de nacimiento de los miembros de su familia en el reverso de una imagen de la Anunciación. A lo largo de las décadas, diferentes escribas agregaron nuevas capas de texto, conformando una cronología familiar que se incorporaba así a los contenidos del libro. La función del códice se veía transformada a través de estas prácticas de apropiación: un objeto devocional se convertía en un depósito de memoria o, como ha dicho Kathryn Rudy (2016), en una "máquina del tiempo" (p. 69). Otra práctica que expresaba la relación particularmente activa que sostenían los lectores medievales con la página era la de corregir los manuscritos. Cuando el propietario de un Libro de Horas encontraba un error en el texto, le encargaba su corrección a un escriba profesional que rasgaba el pergamino para borrar la inscripción inicial y reescribir sobre ella el texto corregido; cuando se trataba de faltas de mayor magnitud, pegaba un trozo de papel o pergamino con el nuevo texto sobre el fragmento erróneo. Algunos propietarios añadían súplicas para la devolución del libro, registraban transacciones o inscribían sus propios nombres en las páginas preliminares o finales. Apropiándose de la página como soporte de escritura, se inscribían a sí mismos en la historia de ese libro (p. 65). Los libros, que pasaban de mano en mano a través de múltiples propietarios, entraban como objetos materiales en una economía circular en que la actualización del manuscrito era un proceso incesante. Desde los primeros códices copiados en los monasterios europeos, la página medieval se caracterizó por su porosidad: los usuarios del libro sintieron una
2. Roberts Hours (MS Ii.6.2), University of Cambridge Library. Recuperado en http://cudl.lib. cam.ac.uk/view/MS-II-00006-00002/33. 


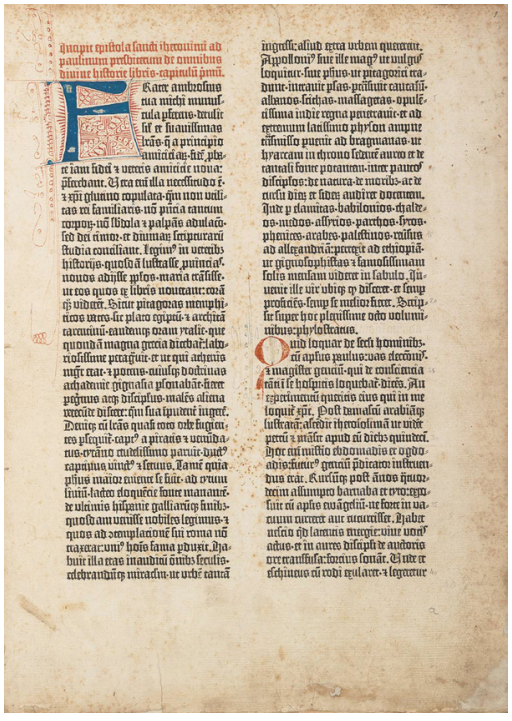

Figura 7. Biblia de 42 líneas. Johann Gutenberg, Maguncia, 1455. Library of Congress.

3. "Propongo la idea del libro premoderno: un objeto que (tanto si es escrito a mano como si es reproducido mecánicamente) era entendido como un objeto individual en su propio tiempo

$y$, en bibliografía moderna, puede ser descrito como un objeto individual en nuestro tiempo" (Lerer, 2015, p. 19). fuerte necesidad de intervenirla. La mayoría de los manuscritos medievales existentes tiene al menos algún texto añadido en sus espacios en blanco, agregar texto era una forma habitual de aumentar y personalizar un libro para sus lectores, y los manuscritos se comportaban como entidades en constante flujo, siempre disponibles para ser remodelados por sus propietarios.

\section{El libro impreso y la construcción de la página moderna}

Luego de la invención de la imprenta, la forma física del códice no cambió sustancialmente en ninguno de sus aspectos (Lyons, 2012). La voluntad de conformarse al modelo del manuscrito fue probablemente movilizada tanto por una necesidad de vincularse a la escritura manual -la "huella visible" primaria del texto- como a la de responder a las necesidades y hábitos de lectura de los destinatarios que conformaban el nuevo mercado del libro (Barbier, 2017). La apariencia del libro manuscrito formaba parte de las concepciones culturales dominantes respecto de la reproducción de textos y los primeros impresores se habían vinculado con la escritura puesta en página a través de sus características verbales y visuales (Figura 7).

Durante la última mitad del siglo $\mathrm{XV}$, los impresores convinieron en un sistema de formatos de libros originados en la cuartilla de cuatro folios del libro manuscrito, el quaternio. Los libros de mayor tamaño eran llamados folios y eran formados a partir de hojas de papel o pergamino dobladas por la mitad y unidas en cuadernos, cada uno compuesto por grupos de entre dos y cinco folios. Los libros en quarto se componían plegando una hoja de papel por la mitad y volviéndola a plegar en dos una vez más, disponiendo de cuatro hojas -ocho páginas- que producían un formato correspondiente a la mitad de un libro en folio. Los octavos correspondían a un cuaderno en quarto que era plegado una vez más, obteniendo una cuartilla de cuatro piezas individuales de papel, de ocho hojas o dieciséis páginas, de la misma manera que se producían los cuadernillos de pergamino tradicionales (Houston, 2016). Frecuentemente, la elección de formatos de página por parte de los impresores respondió a decisiones relacionadas con el tipo de texto publicado. Gutenberg imprimió su Biblia de cuarenta y dos líneas en folio, imitando los grandiosos formatos manuscritos de la época, y lo mismo hizo Colard Mansion en 1476 al imprimir De la Ruine des Nobles hommes et femmes, el primer libro impreso con grabados en planchas de cobre. Lord Chesterfield expresaría en el siglo XVIII esta correspondencia entre categorías de textos y formatos de libros:

Converso con los folios serios en la mañana, cuando mi mente está más clara y mi atención más alerta; tomo los quartos menos severos después de la cena; y por la noche escojo la variada compañía y el entretenido parloteo de los octavos y los duodecimos. (Beal, 2008, p. 158)

La numeración de folios, los encabezados de página, las glosas y comentarios, los incipit y colofones, los elementos que dividen el texto en secciones, las tablas de contenidos y -sobre todo- las capitulares, rúbricas y ornamentaciones que podemos ver en muchos incunables ya habían sido desarrollados -o intuidos con diversos grados de elaboración- en la confección de los manuscritos medievales.

La utilización de capitulares en los primeros libros producidos en talleres tipográficos evidencia el carácter híbrido del libro impreso. Al componer los 
pliegos en sus talleres, los impresores -como los antiguos copistas- reservaban en la superficie de papel o pergamino los espacios previamente destinados a la aplicación de capitulares o elementos decorativos.

Este producto híbrido era individuado de manera accidental -como resultado de los errores cometidos en el taller- o de forma deliberada -a través de las intervenciones realizadas en la postproducción del volumen o por algún usuario posterior- y esto permitía que en un mismo objeto material cohabitaran dos modos de producción -los de reproducción manual y los mecánicos- en una compleja relación de similitudes y diferencias (Lerer, 2015). Los libros impresos se convertían en objetos únicos en el momento en que un escriba profesional trazaba una capitular al inicio de un párrafo, o añadía una rúbrica bajo el título, y los propios usuarios adornaban o personalizaban sus libros, lo que reforzaba el carácter individual de ese ejemplar. Como los manuscritos, los libros impresos entre el siglo XV y el XVII eran cada uno un objeto diferente $y$, en este sentido, libros premodernos 3 :

Un libro impreso moderno es el que resulta de un sistema que no ha sido diseñado para crear copias individuales y únicas, sino (idealmente) réplicas exactamente idénticas. Un libro moderno no es tanto un objeto en sí mismo como una representación de una clase de objetos. Cuando compramos un libro en una tienda o retiramos otro de una biblioteca esperamos que sea exactamente el mismo que cualquier otra copia posible de ser adquirida o tomada en préstamo en cualquier lugar del mundo. (Lerer, 2015, p. 17)

Las formas mecánicas de reproducción propias de la imprenta permitieron, a su vez, el desarrollo de prácticas compositivas que, con el tiempo, permitirían la emergencia del libro moderno como lo entiende Lerer. A través de las matrices de impresión, la impresión tipográfica permitió asignarle un valor de uniformidad a la aplicación de los elementos en la página: ubicaciones regulares dentro de la superficie de impresión, tamaño de caracteres, posición del bloque de texto y repetición uniforme de los elementos permanentes a lo largo del libro. Se inicia así un proceso de estandarización de la página impresa, o más exactamente una profundización del trabajo de organización ya desarrollado a partir del siglo XII por los productores de libros manuscritos. Las operaciones de estructuración del texto se habían sistematizado especialmente impulsadas por las prácticas de clasificación, lectura y consulta de textos originadas en los centros universitarios europeos.

La numeración de folios y la incorporación de glosas son prácticas vinculadas a la necesidad de desarrollar herramientas de acceso y navegación de los textos. Y las tablas de contenidos son un dispositivo especialmente expresivo de esa voluntad.

El Liber chronicarum -una narración de la historia universal basada en la Biblia impresa por Anton Koberger en 1493- se inicia con el anuncio de una tabla alfabética de los contenidos del libro, compuesta con grandes caracteres xilografiados dispuestos sobre la página a la manera de una página de títulos, sin otro elemento más que el propio texto enunciado. La tabla que le sigue organiza en dos columnas los nombres de lugares y personas mencionados en el texto, indicando para cada ocurrencia el asunto al que el pasaje se refiere y señalando en numerales romanos el folio al que el lector debe dirigirse. El Liber chronicarum expresa muy elocuentemente la pretensión de estructurar 


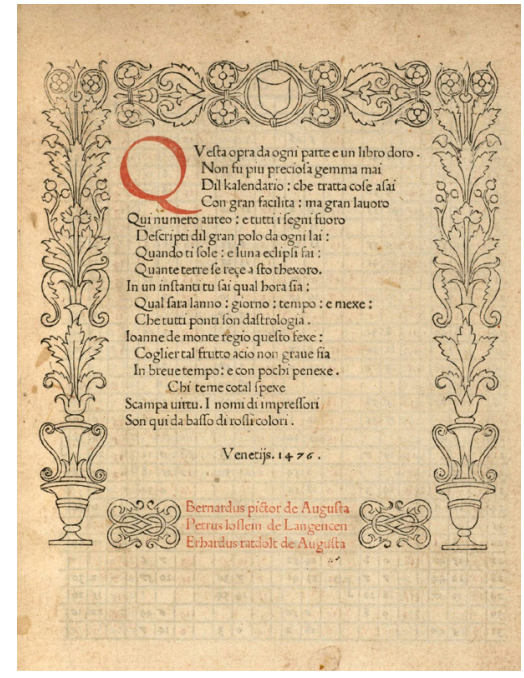

Figura 8. Calendarium. Erhard Ratdolt, Venecia, 1476. Universität Wien. la página, pues alterna diversos tipos de discursos verbales e iconográficos: títulos, textos históricos o explicativos, listados de elementos, textos en verso, retratos, mapas, genealogías. La complejidad de su puesta en página nos dice mucho acerca de cómo esa necesidad de organizar la información se continuó desarrollando con la irrupción de la imprenta de tipos móviles.

\section{El estado civil del libro}

La página de títulos es el dispositivo que registra y nos informa el "estado civil" de un libro (Febvre y Martin, 2012, p. 82). Tal como hoy la conocemos, contiene el nombre del autor, el de la obra, nos dice quién y dónde produjo ese volumen, y en ocasiones nos informará el nombre del traductor, o el de quién estuvo a cargo de la edición de esa colección específica de textos. Durante el siglo XV, las señas de identidad del libro debían ser buscadas al interior del texto o en sus bordes: en el incipit que anunciaba un relato al comienzo del texto o en el colofón emplazado en las páginas finales del volumen.

La primera aparición de un título en una página independiente -un título aislado, solitario- se la debemos a Fust y Schoeffer, en la Bulla cruciatae contra turcos de 1463. El alemán Erhard Ratdolt realizó en Venecia la más temprana página de títulos completa, en la impresión de su Calendarium de 1476: consignaba el nombre de la obra, los de Ratdolt y sus colaboradores y el lugar y la fecha de impresión del volumen (Figura 8). Hacia el año 1500, la página de títulos ya había adquirido una posición propia entre los elementos constitutivos del libro. La aparición y la evolución de la página de títulos respondieron al menos a dos necesidades. Una eminentemente práctica: en los primeros años de la imprenta los libros eran almacenados y transportados sin sus encuadernaciones, las que eran añadidas posteriormente por los usuarios o por un especialista externo al taller de impresión. Los impresores decidieron conservar una primera página el blanco, con el objeto de proteger el libro. Sin embargo, esta página inicial ocultaba la identidad del texto y, para resolver esa dificultad, en los talleres de impresión se adoptó la práctica de añadir un título que designara el contenido del volumen.

Se produjo así una migración general de información desde las páginas finales del libro hacia las preliminares: la información que en un inicio se ubicaba en el colofón -el nombre de la obra, la fecha y el lugar del acabado, el nombre y la marca del impresor- se trasladó a la página de títulos. Una vez que los talleres de impresión se diseminaron por Europa y se establecieron redes de distribución comercial de libros, se hizo evidente para los impresores una segunda necesidad: la de publicitar sus productos en un entorno cada vez más competitivo. Cuando el libro se convirtió en objeto de intercambio, la página de títulos se transformó en un lugar privilegiado para su identificación como producto del trabajo de los impresores, en un instrumento de construcción de prestigio cultural y en un modo de insertar el libro en el espacio público.

Esta necesidad promocional impulsó la incorporación de nuevos elementos a la página de títulos y el desarrollo de nuevas formas compositivas. Las planchas grabadas de cobre -una innovación inglesa de mediados del siglo XVI- permitieron producir una página de títulos suntuosamente ornamentada, para intentar transmitir la materia del texto a sus potenciales lectores. Recurrentemente los grabados representaban arcos, pórticos o columnas, como si pretendieran asignarle a esta página el estatuto de vía legítima de acceso al texto. 

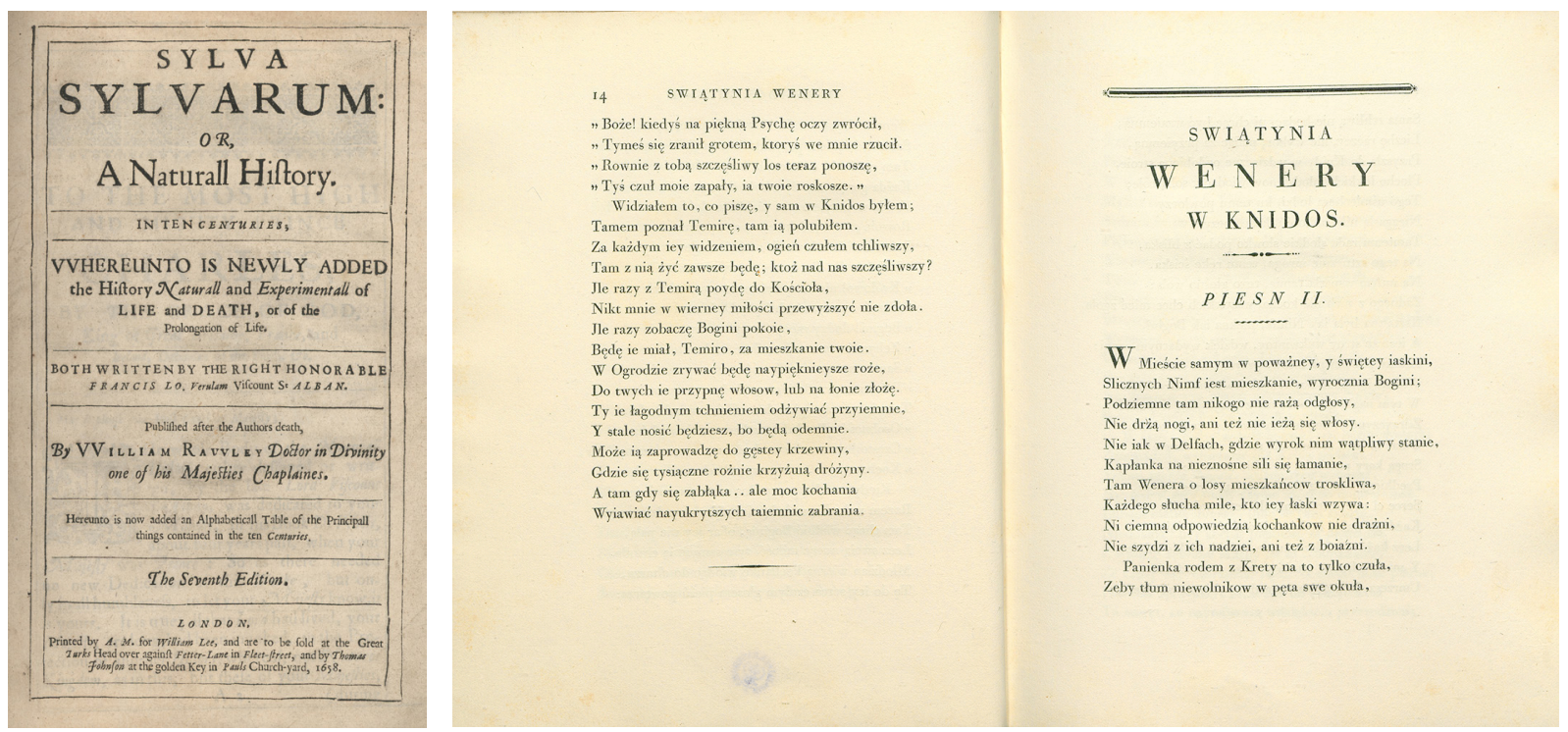

Entre los siglos XVI y XVII, las páginas de títulos fueron utilizadas por los libreros y editores como un instrumento de promoción de sus publicaciones, pegándolas como afiches en las calles (Gaskell, 2012)4. Esta práctica publicitaria se expresó en un modo particular de disponer los textos en la página, desplegando la mayor cantidad posible de información y jerarquizándola según sus diferentes niveles de relevancia por medio del tamaño de los tipos utilizados. Un ejemplo de este modo de componer la página puede ser encontrado en la edición de 1658 del Sylva Sylvarum, de Francis Bacon, publicada en Londres por William Rawley (Figura 9).

Las tendencias neoclásicas del siglo XVIII europeo estimularon la simplificación del diseño y la eliminación de las decoraciones innecesarias de la página de títulos. Los elegantes caracteres para impresión, diseñados por tipógrafos como Giambattista Bodoni (Figura 10) y John Baskerville, permitieron darle forma a esta manera de concebir el espacio tipográfico, y su propio trabajo como impresores produjo páginas de títulos compuestas con una administración sutil y precisa de los espaciados, un rango limitado de tamaños de los caracteres y una variedad todavía más restringida de familias tipográficas (Cole, 1971).

Este proceso de simplificación de los elementos que conforman la página se terminó por consolidar en el libro moderno, estabilizando su configuración y sus jerarquías internas. En lo fundamental, la página de títulos contemporánea contiene un conjunto de elementos bastante similar al que podemos encontrar en las páginas de Bodoni o Baskerville: el nombre del autor y de la obra, en ocasiones los de algunos colaboradores -traductores, ilustradores, compiladores-, el nombre del editor -que ha reemplazado al del impresor- $y$ en ocasiones una indicación genérica: "poemas", "novela".

La página de títulos, una vez alcanzado su estado completo de desarrollo, se consolidó como un dispositivo obligatorio de atribución del texto y del objeto material, capaz de darle presencia al texto y "asegurar su existencia en el mundo" (Genette, 2001, p. 7). Si el destinatario del texto es el lector, el del título es el espacio público.

Con la página de títulos se termina de estructurar la secuencia de las diferentes unidades textuales y visuales que dan forma al libro: las páginas prelimi-
Figura 9. Páginas de títulos de Sylva sylvarum, or, a natural history, impresa por William Rawlleyen, en Londres (1658). University of Sydney Library.

Figura 10. Le Temple de Gnide (edición en polaco), Montesquieu. Giambattista Bodoni, Parma, 1807. Biblioteka Narodowa, Varsovia.

4."Pegada en las tiendas de los libreros, montada en estacas, colgando de las puertas de los comercios, clavada en los postes públicos y aun pegada en las puertas de las iglesias, la página de títulos actuó como un volante para publicitar las obras por venir y las ya disponibles" (Shevlin, 1999, p. 48). 
nares -títulos y portadillas, prefacios, dedicatorias y prólogos- fabrican un contexto, entregan algunas indicaciones para el acceso al texto. Las divisiones internas establecen ciertas jerarquías y órdenes de lectura, y las páginas finales - posfacios, epílogos, colofones- conducen el argumento a una conclusión y a la elaboración de una impresión final en el lector (Mak, 2011, p. 34).

\section{Discusión}

La invención del códice -entre los siglos II y IV- supuso una transformación fundamental en los modos de transmisión de textos y contener información. Las operaciones implícitas en su elaboración -la reunión de folios en cuadernos, su unión por medio de una costura, la encuadernación del volumen por medio de una cubierta- se constituyeron en un procedimiento de producción que ha caracterizado al libro como artefacto hasta nuestros días. Sin embargo, el modo de componer la página en los primeros códices heredó algunas prácticas ya utilizadas en los rollos de papiro, como la organización del texto en columnas verticales.

Así mismo, el advenimiento de la imprenta desencadenó una serie de transformaciones en el mercado del libro y -por supuesto- en los modos de componer la página. El sistema de impresión ideado por Gutenberg hizo posible la reproducción mecánica de copias múltiples de un texto previamente editado y permitió introducir formas cada vez más sistemáticas de organización de la información sobre su soporte. Este proceso de reglamentación de las formas de la página -sin embargo- operan como profundizaciones de los intentos desarrollados previamente por los copistas medievales. Los primeros impresores trasladaron a los libros su manera de comprender la materialidad del códice, para volcar en el libro impreso las formas propias del manuscrito. Las formas de la página manuscrita, ya dotadas de consistencia en su diseño, fueron heredadas -y luego perfeccionadas- por el libro impreso.

Si bien la invención del códice, la aparición de la imprenta o la industrialización en la fabricación del papel produjeron enormes transformaciones en las condiciones de producción y distribución de textos, al observar los modos particulares de organización del texto sobre la página a lo largo del tiempo, podemos identificar una misma necesidad de administrar la página como espacio cognitivo, como superficie de interacción entre el autor, texto, el diseñador y el lector.

\section{Conclusión}

El libro como soporte de transmisión de textos es una tecnología fluida, que cambia. Su estructura fundamental se ha conservado durante mil seiscientos años, ha visto reflejadas sobre sí las transformaciones tecnológicas y los cambios culturales producidos en ese periodo, y en ese proceso se han transformado también las formas de organizar los elementos que lo constituyen. Si bien algunas de esas transformaciones han producido efectos relevantes para su desarrollo como producto cultural -la invención del pergamino, la aparición de la imprenta, la fabricación industrial del papel, la automatización de la imprenta- podemos advertir una larga cadena de continuidades en ese proceso y entender el libro como un mismo objeto que se supera a sí mismo sin dejar de ser lo que es. La necesidad de dividir el texto en secciones -por medio de incipit o subtítulos- o la de entregarle al lector herramientas para moverse a lo largo del texto -como sucede con los encabezados de página o las numeraciones de folios- son gestos editoriales tan antiguos como el propio códice. La página es un espacio privilegiado de interacción entre el productor 
del libro, el texto y el lector, y sobre su superficie han tenido lugar buena parte de las transformaciones que han dirigido el desarrollo del libro como artefacto hasta el presente. Anclada en las antiguas tradiciones fundantes del códice y el crecimiento desde ellas, en la página podemos reconocer hasta nuestros días el gesto fundamental que anima al libro: la voluntad de contener, organizar y transmitir conocimiento.

\section{Referencias}

Barbier, F. (2017). Gutenberg's Europe. The Book and the Invention of Western Modernity. Cambridge: Polity Press.

Beal, P. (2008). A Dictionary of English Manuscript Terminology: 1450 to 2000 . Nueva York: Oxford University Press.

Cole, G. (1971). The Historical Development of the Title Page. The Journal of Library History, 6 (4), pp. 303-316.

Gamble, H. Y. (1995). Books and Readers in the Early Church. A History of Early Christian Texts. New Haven: Yale University Press.

Febvre, L., y H-J Martin (2014). La aparición del libro. Ciudad de México: Fondo de Cultura Económica.

Gaskell, P. (2012). A New Introduction to Bibliography. New Castle: Oak Noll Press.

Genette, G. (2001). Umbrales. Ciudad de México: Siglo Veintiuno.

Houston, K. (2016). The Book: A Cover-to-Cover Exploration of the Most Powerful Object of Our Time. Nueva York: Norton. Kilgour, F. G. (1998). The Evolution of the Book. Nueva York: Oxford University Press.

Lyons, M. (2012). Historia de la lectura y de la escritura en el mundo occidental. Buenos Aires: Editoras del Calderón.
Lerer, S. (2015). "Bibliographical Theory and the Textuality of the Codex: Toward a History of the Premodern Book", en M. Johnston, M. y M. Van Dussen, eds. (2015), The Medieval Manuscript Book: Cultural Approaches. Cambridge: Cambridge University Press.

Mak, B. (2011). How the Page Matters. Toronto: University of Toronto Press.

Rudy, K. M. (2016). Piety in Pieces. How Medieval Readers Customized their Manuscripts. Cambridge: Open Book Publishers.

Shevlin, E. (1999). "To Reconcile Book and Title, and Make 'em Kin to One Another": The Evolution of the Title's Contractual Functions, Book History, 2, 42-77.

Smith, M. (1997). "The End-Title, the Early Title-Page and the Wrapper: Their Inter-connections". Transactions of the Cambridge Bibliographical Society, 11 (2), 95-111.

Utsch, A. (2014). "História da encadernação e restauração de acervos bibliográficos: estatutos simbólicos e práticas escriturárias". Revista Escritos, 8 (8), 159-179. 